\title{
News Shocks and the Slope of the Term Structure of Interest Rates: Comment
}

\author{
Danilo Cascaldi-Garcia*
}

April 2016

\begin{abstract}
Kurmann and Otrok (2013) show that the effects on economic activity from news on future productivity growth are similar to the effects from unexpected changes in the slope of the yield curve. This comment shows that these results do not hold in the light of a recent update in the utilization-adjusted total factor productivity series produced by Fernald (2014).
\end{abstract}

The economic findings of Beaudry and Portier (2006) contributed to the literature on business cycles driven by agents' beliefs with the empirical identification of the 'news shock' - changes in the future total factor productivity (TFP) that are foreseen by the economic agents. The idea behind the news shock is that future technological improvements (free from utilization factors) take time until they have an impact on the economy. From a rational expectations perspective, the agents can foresee this technological impact (up to some extent) and react to it now.

Kurmann and Otrok (2013) provide the most important result of the relationship between a news shock and other economic shocks in the literature. They report a correlation of 0.86 between a news shock and the shock to the slope of the term structure, defined as

\footnotetext{
*Cascaldi-Garcia: Warwick Business School, University of Warwick, Coventry, CV4 7AL, Danilo.Garcia.14@mail.wbs.ac.uk. I would like to thank John Fernald, Ana Galvão, André Kurmann and Christopher Otrok for valuable comments and insights. I also would like to thank Anthony Garratt, Kolja Johannsen, Ingomar Krohn, Michael Moore and the participants at the International Conference on Computational and Financial Econometrics (CFE 2015) for comments on earlier versions of this paper. This research is funded by a scholarship from CAPES - Brazil.
} 
the spread between the yield on a long-term treasury bond and a short-term bill rate. As emphasized by Kurmann and Otrok (2013), it is known from the finance and business cycle literatures that the slope of the term structure (i) carries information that helps to predict macroeconomic activity ${ }^{1}$ and (ii) relates to the transmission of monetary policy.

Adopting a procedure of identification of structural shocks by maximizing the forecast error variance of a target variable ${ }^{2}$, Kurmann and Otrok (2013) show that the link between monetary policy transmission and economic activity is the relation between news shocks and the slope of the term structure. A positive slope shock foresees smooth future growth in consumption and utilization-adjusted TFP, accompanied by a drop in inflation. Interestingly, this is also the predicted behaviour of a news shock as in Beaudry and Portier (2006). The increase in the slope comes from a stronger response of the policy rate than the long rate, with the Federal Funds rate falling more than the inflation. Since the economic responses after a slope shock are identical to a news shock, the authors conclude that the uneven effect between the short and long run rates is the endogenous response of the monetary policy to a news shock.

As a result, both slope and news shocks are supposedly measuring the same economic effect. The authors also confirm these similarities showing that news shocks explain more than half of the movements in the slope. This comment presents evidence that this strong relationship between news and slope of the term structure does not hold anymore. After an update in the utilization-adjusted TFP series adopted by Kurmann and Otrok (2013), the correlation between news and slope shocks falls to zero and the impulse responses of these shocks are substantially different.

The identification of the news shock in Kurmann and Otrok (2013) relies on the quarterly utilization-adjusted TFP series from Fernald (2014). Beaudry and Portier (2006) emphasize that when considering the identification of a news shock it is very important to control for utilization factors, capturing as closely as possible the effects of a technological change. Therefore, measures of raw TFP are not suitable to identify news shocks because their unexpected changes may be related with variations in factors utilization instead of technology changes.

Fernald (2014) applies growth-accounting methods for imputation of capital and labour

\footnotetext{
${ }^{1}$ See Harvey (1988), Estrella and Hardouvelis (1991), Ang and Piazzesi (2003) and Kurmann and Otrok (2013).

${ }^{2}$ As in Faust (1998), Uhlig (2005) and Barsky and Sims (2011).
} 
controlling for heterogeneity, and adjustments for variations in factor utilization (including non-technological factors, such as the intensity margin for the workweek of capital and labour effort). Initially adopted by Beaudry and Portier (2006), it became a common practice in the news shock literature to use this series for identification purposes (see, for example, Barsky and Sims (2011), Barsky et al. (2014), Forni et al. (2014) and Beaudry and Portier (2014)).

The utilization-adjusted TFP series is constantly updated by the author, and went through severe revisions in 2014. The main changes are the parameter estimates on utilization (from the Basu et al., 2006 methodology to Basu et al., 2013) and the imputation of hours per worker. The result of this update is a substantial change in the utilization factor and, consequently, in the utilization-adjusted TFP. A simple graph comparison (Figure 1) of the new and old series shows that the non-adjusted TFP is very similar before and after the update of the utilization parameters. However, the utilization factor is substantially different. Here I revisit Kurmann and Otrok (2013) in the light of these changes.

The structure of this comment is as follows. In Section 1, I show that the Kurmann and Otrok (2013) results are sensitive to updates in the utilization-adjusted TFP series from Fernald (2014) by replicating these results with a new version of the series. Section 2 is a robustness check, showing that an alternative model comprising a different information set, time span and slope measure is also sensitive to the update in the utilization-adjusted TFP series. In Section 3, I show that a slope shock produces a positive impact on the utilization factor, indicating that the relation of slope and TFP found in Kurmann and Otrok (2013) can be some remaining effect of utilization. Section 4 concludes the discussion.

\section{Revisiting Kurmann and Otrok (2013) with a new TFP series}

I start evaluating the connection between news and slope shocks from Kurmann and Otrok (2013) with the new utilization-adjusted TFP series. This first exercise consists of estimating exactly the same model as Kurmann and Otrok (2013) for news and slope shocks, but considering the updated utilization-adjusted TFP series from Fernald (2014). I adopt the code made available by the authors, with the same variables and time period.

With the original database, the correlation coefficient between the recovered news and 
Figure 1: Old and new Fernald (2014) TFP series decomposed by utilization factor
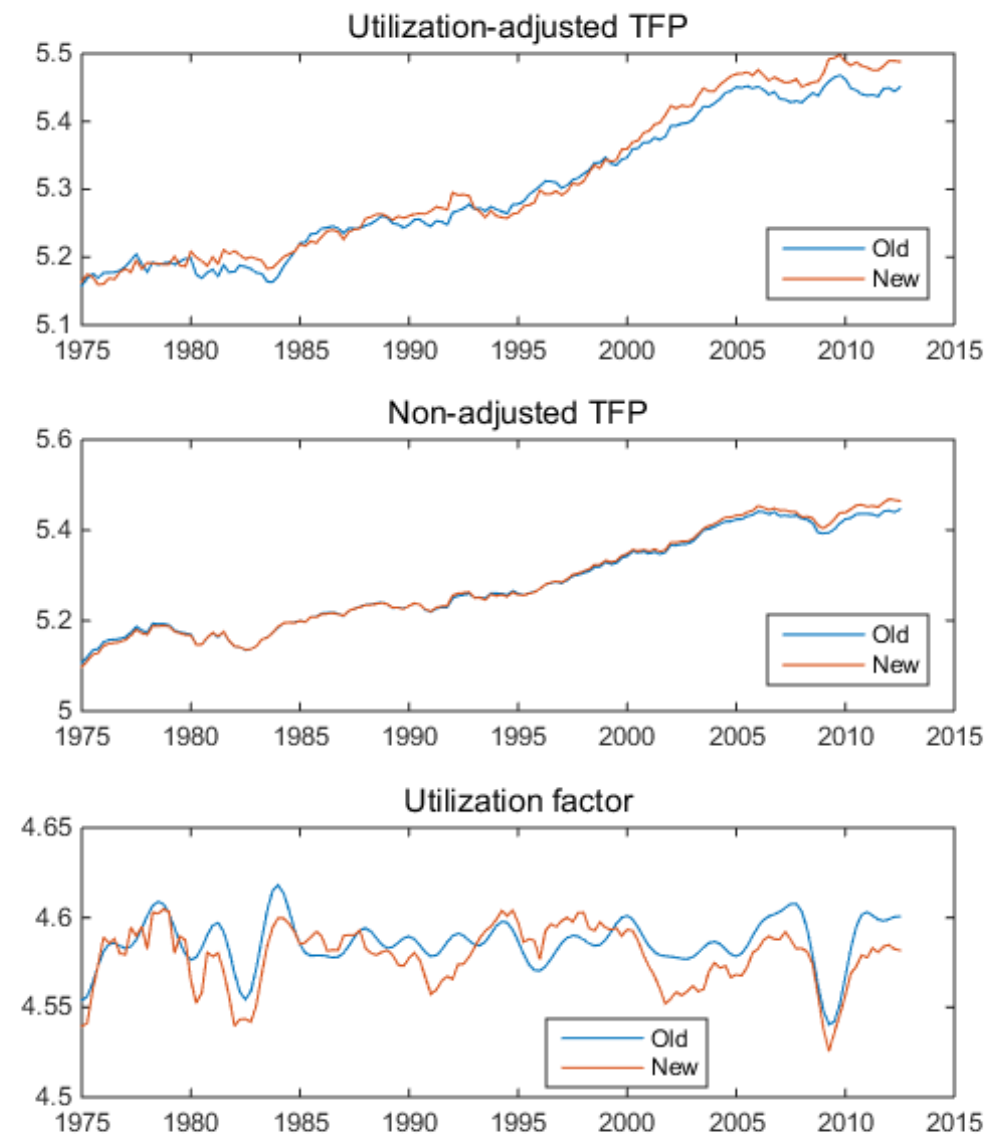

Calculation from the series available at Federal Reserve Bank of San Francisco (new utilization-adjusted TFP - Nov/2015 vintage) and from Beaudry and Portier (2014) database (old utilization-adjusted TFP - Nov/2012 vintage).

slope shocks is 0.86 (Kurmann and Otrok, 2013). This result is substantially distinct when I adopt the new updated utilization-adjusted TFP $\operatorname{series}^{3}$ : the correlation between news and slope shocks now is only 0.14 . This drop in the correlation is also robust to different vintages of the utilization-adjusted TFP series ${ }^{4}$. For example, adopting the vintage of May/2013, the correlation is of 0.82 ; considering the vintage of May/2014, the correlation falls to 0.38; finally, with the vintage of May/2015, the correlation decreases to 0.18.

The economic responses of slope and news shocks are also notably different, as shown

\footnotetext{
${ }^{3}$ TFP series downloaded in November/2015 from the Federal Reserve Bank of San Francisco (http://www.frbsf.org/economic-research/economists/john-fernald/).

${ }^{4}$ John Fernald, via email correspondence in March 2016, has kindly provided me with utilization-adjusted TFP vintages from 2013 to 2015.
} 
in Figures 2 and 3. Figure 2 provides the impulse response functions of the slope shock, with the solid lines representing the model with the new utilization-adjusted TFP series. The dashed lines represent the model with the old utilization-adjusted TFP series (as in Kurmann and Otrok, 2013). With the old series, the path of the impulse response on the utilization-adjusted TFP resembles a news shock, with zero effect on impact and smoothly converging to a new higher level (top-right graph from Figure 2). However, with the updated utilization-adjusted TFP series there is a positive and statistically significant effect on impact $(t=0)$. The slope shock is now capturing the positive effect of technological growth, and not an anticipated slow smooth diffusion of technology (as in a news shock).

Figure 2: Comparing responses to a slope shock with the new and old versions of the utilization-adjusted TFP under the Kurmann and Otrok (2013) model
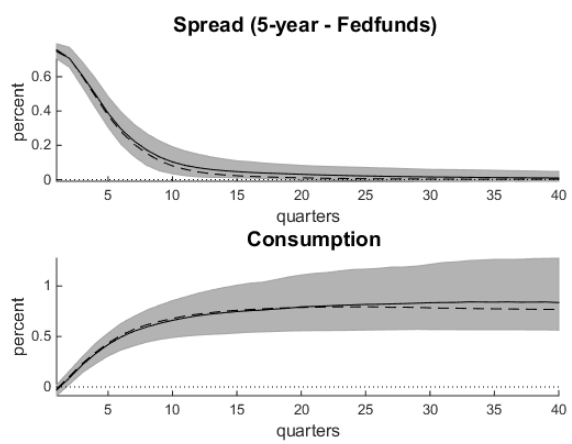

Federal Funds rate

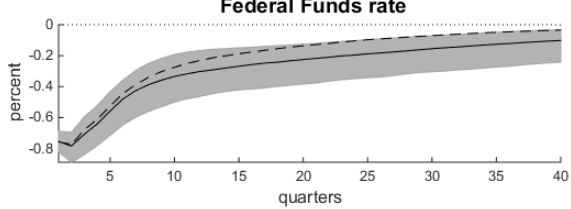

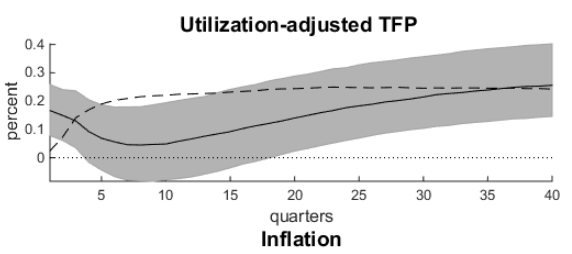
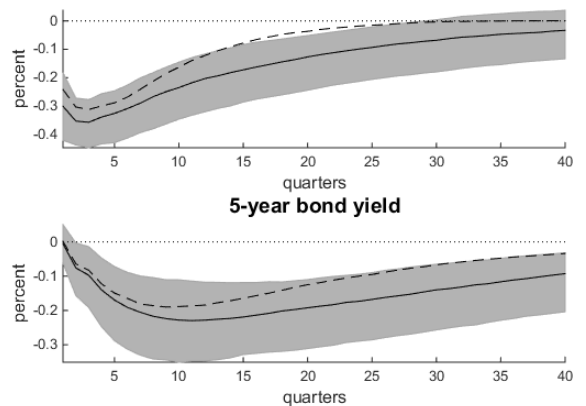

The solid line is the median effect with the revised utilization-adjusted TFP series, and the dashed is with the old utilization-adjusted TFP series. The grey area corresponds to the 16\%-84\% coverage bands of the model considering the new utilization-adjusted TFP series.

The similarities between the impulse responses after a slope shock with a news shock is the basis of the argument that variations in the slope are the endogenous monetary response to future technological changes. The implications of the slope shock on monetary policy from Kurmann and Otrok (2013) still holds under the updated utilization-adjusted TFP series, but not as a response to a news shock. First, after a slope shock, inflation falls less than the Federal Funds rate, reducing the real short rate, and showing an active expansionary monetary policy. Second, variations in the slope are a result of the drop in the short- 
run interest rate, since the effect on the long-run (5-year bond yield) is practically zero. Finally, large slopes predict future economic growth (e.g., an expansion in consumption, as in Harvey, 1988), although the effect on utilization-adjusted TFP is now significant on impact.

Figure 3 provides the impulse response functions after a news shock. Again, the solid lines refer to the updated utilization-adjusted TFP series and the dashed lines to the old version. In order to match Kurmann and Otrok (2013), in which a news shock raises the slope of the term structure, the short rate has to decrease faster than the long rate. Here, however, the impact of a news shock on the short and long rate are very similar. As a result, the effect over the slope is nearly zero and not significant. This pattern is different from Kurmann and Otrok (2013) but resembles the DSGE results produced by Kurmann and Otrok $(2011)^{5}$.

Figure 3: Comparing responses to a news shock with the new and old versions of the utilization-adjusted TFP under the Kurmann and Otrok (2013) model
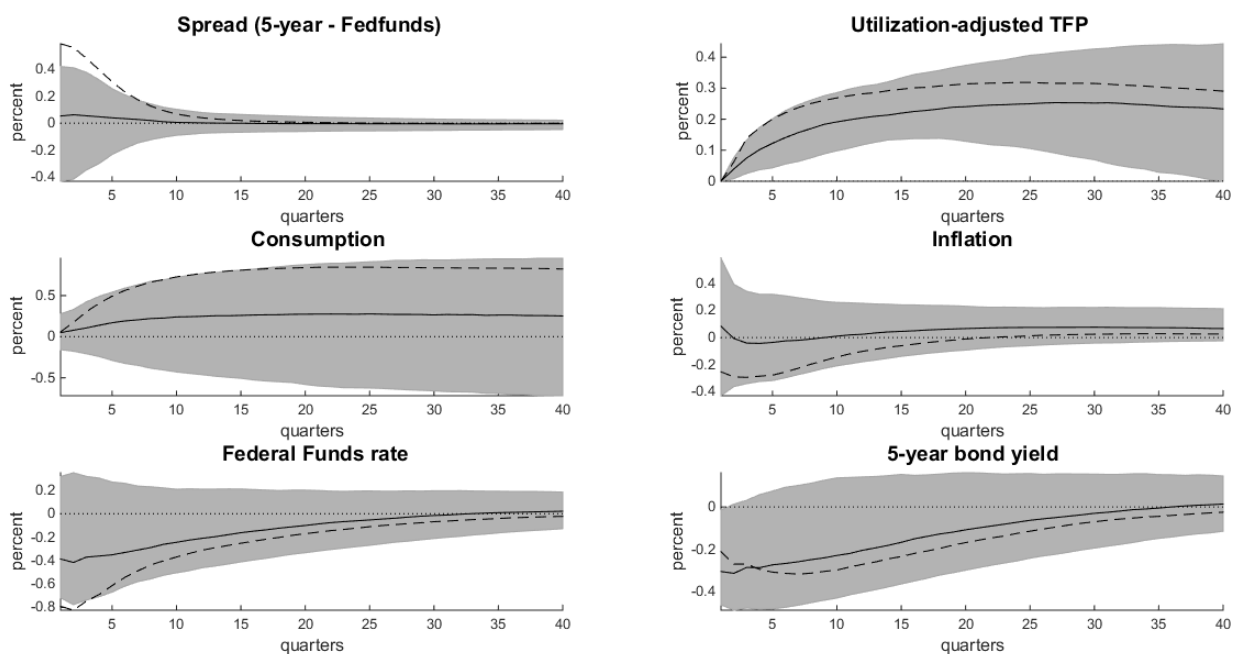

The solid line is the median effect with the revised utilization-adjusted TFP series, and the dashed is with the old utilization-adjusted TFP series. The grey area corresponds to the 16\%-84\% coverage bands of the model considering the new utilization-adjusted TFP series.

The empirical results from Kurmann and Otrok (2013) also show that news shocks account for more than $50 \%$ of the unpredictable movements of the slope of the term structure. When adopting the new updated utilization-adjusted TFP series this share falls to $20 \%$,

\footnotetext{
${ }^{5}$ Adopting estimated DSGE models, the authors show that after a news shock the drop in the short and long rate are about the same.
} 
and the lower coverage band is close to zero (Figure 8 in the Appendix). In summary, the updates performed in the methodology of adjusting TFP for utilization changed the behaviour of both news and slope shocks, but particularly the news shock. The result is that news and slope shocks are no longer as strongly correlated as in Kurmann and Otrok (2013).

\section{Robustness check with a different information set}

In Section 1, I show that the strong relation between news shocks and the slope of the term structure as presented by Kurmann and Otrok (2013) is no longer valid. Two tests are necessary in order to certify that the update in the TFP series is the only cause of the zero correlation between news and slope shocks. First, alternative models with the old utilization-adjusted TFP series should be able to reproduce the high correlation between news and slope shocks. Second, this correlation must disappear when substituting the old utilization-adjusted TFP series for the new updated version.

I propose here an alternative VAR model $^{6}$ incorporating additional financial variables, with relevant forward-looking information that helps to identify the news shock ${ }^{7}$. Since variations in the slope are supposedly responses to news shocks, these new financial variables should also contribute to the identification of the slope shock. This alternative model differs from Kurmann and Otrok (2013) in the variables considered ${ }^{8}$, the time $\operatorname{span}^{9}$ and the measure of the slope of the term structure ${ }^{10}$. The identification of the news and slope

\footnotetext{
${ }^{6}$ Bayesian Vector Autoregressive Model estimated with Minnesota Priors (Litterman, 1986) as suggested by Bańbura et al. (2010) and Carriero et al. (2015).

${ }^{7}$ The presence of forward-looking economic variables, such as consumption and stock prices, is a necessary condition for the proper identification of a news shock (Beaudry and Portier, 2006).

${ }^{8}$ The model consists of a measure of the $\log$ of utilization-adjusted total factor productivity (TFP), log of (real) personal consumption expenditures (PCE), excess bond premium (EBP) - calculated by Gilchrist and Zakrajšek (2012) -, a measure of realized volatility (RVOL), log of industrial production, log of private (nonfarm) payroll employment, log of the PCE price deflator, value-weighted total stock market (log) return, effective nominal Federal Funds rate and the slope of the term structure (defined here as the difference between the 10-year Treasury yield and the effective nominal Federal Funds rate). All the variables are US data and, except for utilization-adjusted TFP, transformed from monthly to quarterly as the mean of the period.

${ }^{9}$ Considering the period from 1975:I to 2007:IV, while Kurmann and Otrok (2013) is from 1959:I to 2005:I. I use data only up to 2007:IV to avoid the effect of the zero lower bound in the identification of the slope shock. I would like to thank Christopher Otrok and André Kurmann for raising the zero lower bound issue.

${ }^{10} \mathrm{I}$ measure the slope of the term structure as the spread between the 10-year Treasury yield and the effective nominal Federal Funds rate, while Kurmann and Otrok (2013) considers the difference between the 60-month Fama-Bliss unsmoothed zero-coupon yield from the CRSP government bonds files and the Federal Funds rate.
} 
shocks follows the maximization of the forecast error variance of the utilization-adjusted TFP and the slope, respectively.

Adopting the old utilization-adjusted TFP series in the alternative VAR model, the recovered news and slope shocks produce a correlation between them of 0.48 , statistically significant at the $1 \%$ level. This correlation is lower than the 0.86 of Kurmann and Otrok (2013), and the reason is the different time span. In Kurmann and Otrok (2013) the data covers 1959:I to 2005:I and the correlation between news and slope shocks is not as strong as 0.86 throughout the entire series. Adopting an 80 quarter moving window, I show in Figure 4 that the correlation is above 0.86 until the first quarter of 2000, falling sharply afterwards. In fact, considering the final sub-sample between 1985:II and 2005:I, the correlation coefficient only accounts for 0.55 . In the alternative VAR model the time span is more up-to-date (from 1975:I to 2007:IV), concentrating the period where the correlation between news and slope shocks is lower ${ }^{11}$.

Figure 4: Correlations between news and slope shocks on an 80 quarter moving window from Kurmann and Otrok (2013)

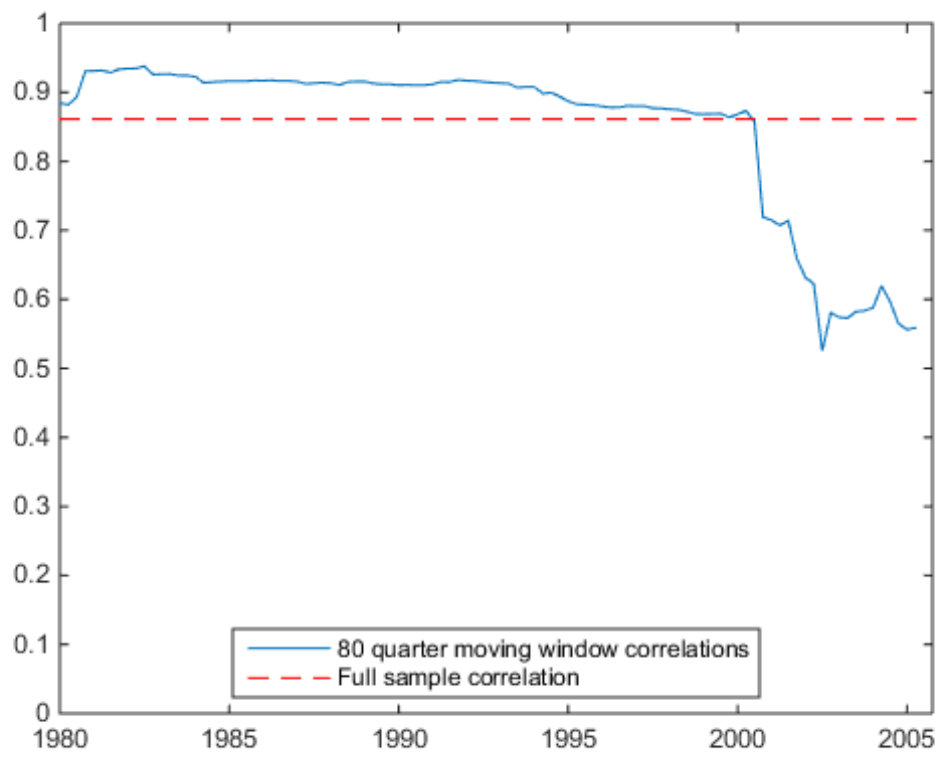

Calculation of correlations between the recovered news and slope shocks over an 80 quarter moving window under the original identification of Kurmann and Otrok (2013). The correlation over the full sample is of 0.86. The date in the horizontal axis corresponds to the final observation of the 80 quarter moving window.

\footnotetext{
${ }^{11}$ I also evaluated the correlation of the alternative VAR model with the old utilization-adjusted TFP series considering an 80 quarter moving window. The results show that the correlation of 0.48 is quite robust all over the series, and can be seen in Figure 9 in the Appendix.
} 
Figure 5: Impulse responses to a news shock under an alternative VAR model augmented by financial variables
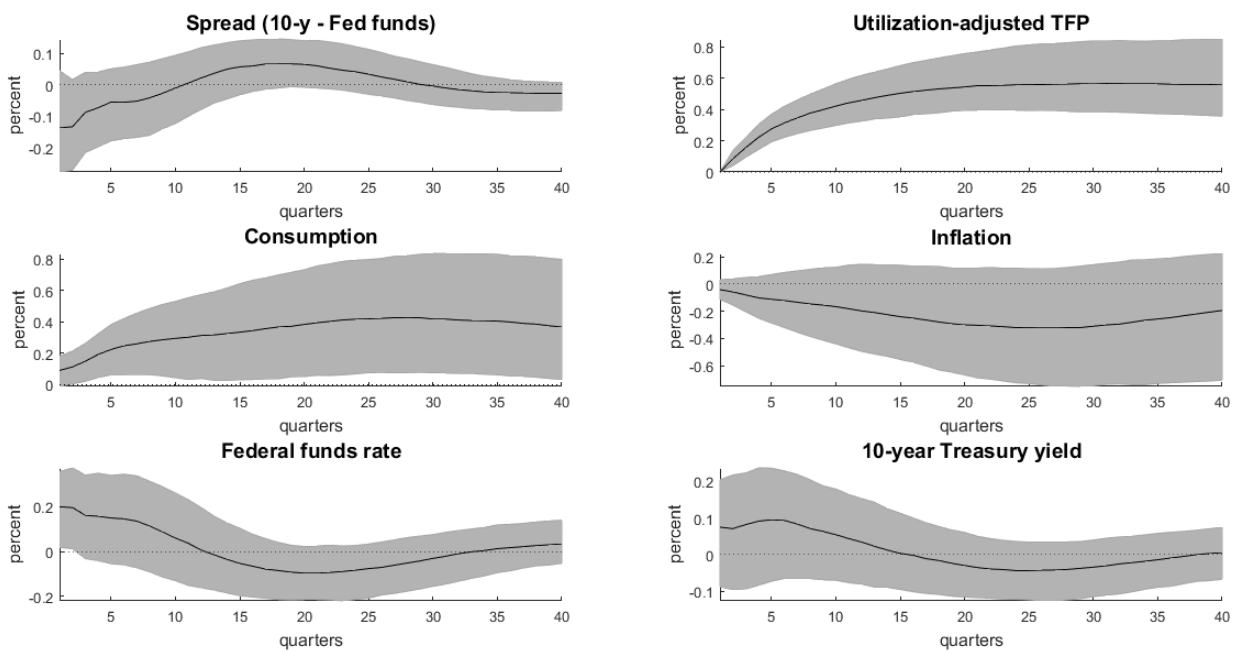

The grey area corresponds to the 16\%-84\% coverage bands of the model after 1000 replications and considering the new TFP series. The 10-year Treasury yield impulse response is a combination of the Federal Funds rate and the spread.

Furthermore, when adopting the new updated utilization-adjusted TFP series, the correlation between the recovered news and slope shocks identified under this model is -0.33 . The news shock explains only $7 \%$ (impact) to $9 \%$ (long-run) of the unpredicted movements of the slope of the term structure. In Kurmann and Otrok (2013), the impulse responses after a news and a slope shock are quite similar, which is not the case here (Figure 5 for the news shock and Figure 6 for the slope shock). Notably, there is no effect on utilization-adjusted TFP after a slope shock under this alternative VAR model. It follows that the positive effect of a slope shock on utilization-adjusted TFP produced by the Kurmann and Otrok (2013) method fades away when the information set is widened with financial variables (Figure 6).

As in Section 1, there is no evidence from this alternative VAR model of a relationship between news shocks and the slope of the term structure after the update in the utilizationadjusted TFP series.

\section{The effect of a slope shock on the utilization factor}

Fernald (2014) argues that the update in the TFP series was caused by a modification in the adjustment for changes in factor utilization from the methodology of Basu et al. (2006) 
Figure 6: Impulse responses to a slope shock under an alternative VAR model augmented by financial variables
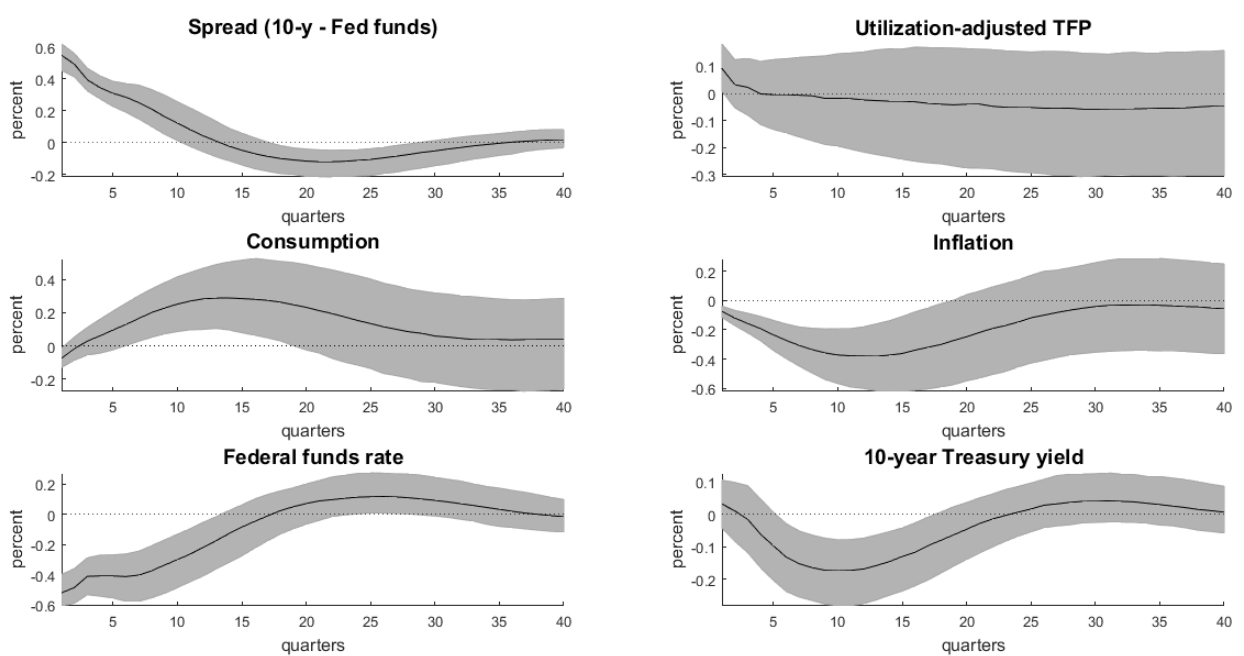

The grey area corresponds to the 16\%-84\% coverage bands of the model after 1000 replications and considering the new TFP series. The 10-year Treasury yield impulse response is a combination of the Federal Funds rate and the spread.

to the one adopted in Basu et al. (2013). Hence, it is reasonable to consider that the new utilization-adjusted TFP series is a more accurate measure of the unobserved changes in technology. In this Section, I check if the relation between news and slope shocks using the older version of the utilization-adjusted TFP series comes from some remaining utilization factor.

A statistically significant effect of a slope shock on utilization would be a good indicator that a share of these factors were still included in the old series. Here I conduct a test to verify this effect by evaluating the impact of a slope shock on the utilization factor under the same alternative VAR model of Section $2^{12}$.

Figure 7 produces the impulse responses of the slope shock in the alternative VAR model with the utilization factor. There is a positive and significant effect on the utilization factor and on the non-adjusted TFP in the medium-run, starting from zero on impact $(t=0)$. The path of the non-adjusted TFP response is very similar to the utilization factor. Since the utilization factor is part of the total TFP, this implies that most of the effect of a slope shock observed is due to a higher utilization and not to a positive change on the non-utilization

\footnotetext{
${ }^{12}$ I replace the updated utilization adjusted TFP series for the non-adjusted TFP series and the utilization factor.
} 
part of the TFP (a proxy for technology change).

From a macroeconomic perspective, the slope shock is predicting future economic activity (higher industrial production and employment), which justifies the positive effect in the utilization. However, in the long-run the responses of a slope shock on macroeconomic variables converge to zero, and the utilization factor also follows this pattern. This transitory effect in the long term of both utilization factor and non-adjusted TFP makes the slope shock remarkably different from a news shock.

While future research on this topic is desirable, these preliminary findings indicate that the positive effect of a slope shock on TFP is driven by the utilization factor and might cause the positive correlation between news and slope shocks presented in Kurmann and Otrok (2013).

Figure 7: Impulse responses to a slope shock under an alternative VAR model augmented by financial variables and the utilization factor
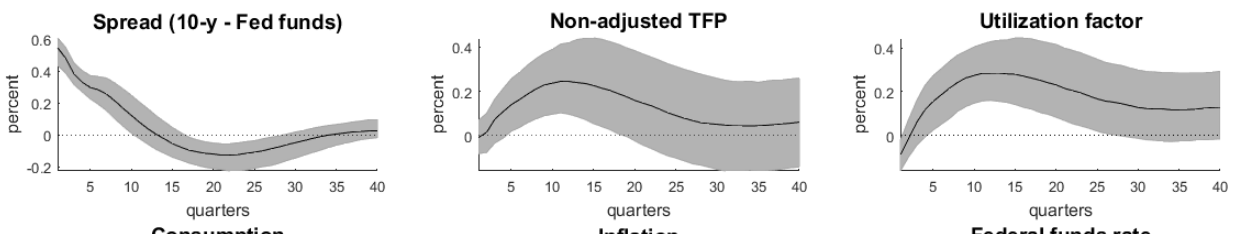

Consumption
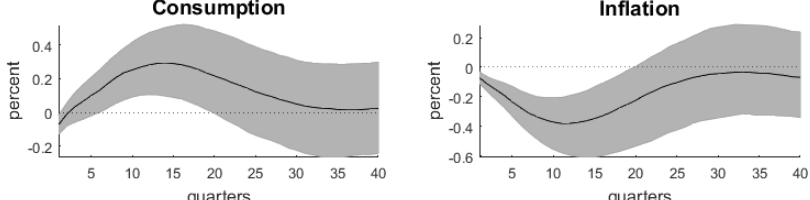

Federal funds rate
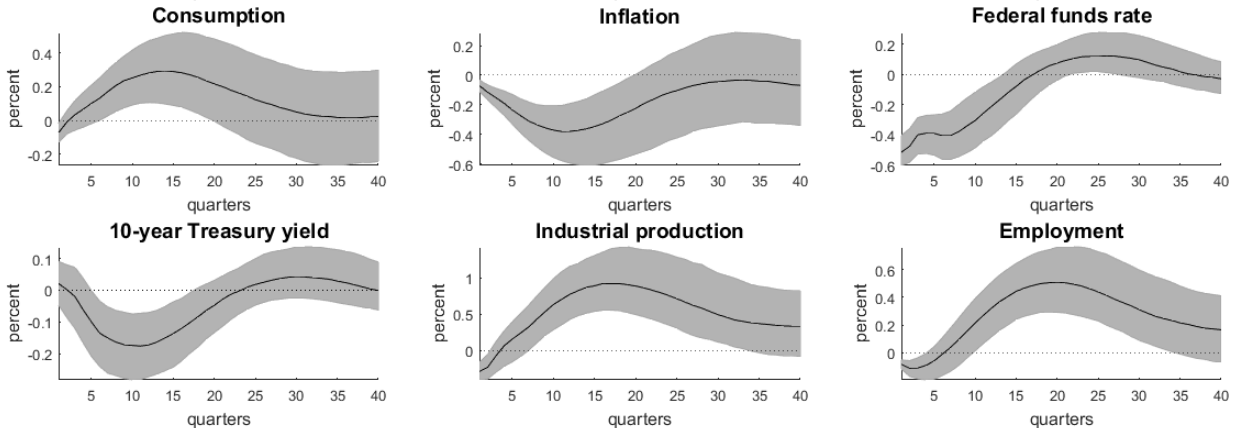

The grey area corresponds to the 16\%-84\% coverage bands of the model after 1000 replications and considering the new TFP series. The 10-year Treasury yield impulse response is a combination of the Federal Funds rate and the spread.

\section{Conclusion}

In this comment I provide evidence that the methodology of extracting the utilization factor from TFP influences the correlation between news and slope shocks, and how economic variables respond to a news shock. The identification of a news shock depends on properly 
controlling for utilization factors, and the revision on the utilization-adjusted TFP series has a substantial impact on this. Without the adjustment, the response in TFP after a productivity shock may be due to changes in factor utilization, and not in technology itself. Potentially, important results from the news shock literature that rely on the utilizationadjusted TFP series from Fernald (2014) may be also affected by this revision.

After the update of the utilization-adjusted TFP series, the correlation between news and slope shocks vanishes and the implications of a news shock become substantially different from Kurmann and Otrok (2013). The main reason for the positive effect of a news shock on the slope in Kurmann and Otrok (2013) is the endogenous response of monetary policy, driven through the fall of the Federal Funds rate in a larger level than the long-term yield. However, with the new updated utilization-adjusted TFP series the effect of a news shock on inflation is zero, and the drop in the Federal Funds rate is not statistically significant (Figure 3), invalidating the 'active monetary policy' channel of a news shock on the slope. As a result, it is no longer possible to conclude that systematic monetary policy is a channel of linking macroeconomic news shocks and term structure dynamics, as initially proposed by Kurmann and Otrok (2013).

\section{References}

Ang, A. and Piazzesi, M. (2003). A no-arbitrage vector autoregression of term structure dynamics with macroeconomic and latent variables. Journal of Monetary Economics, $50(4): 745-787$.

Bańbura, M., Giannone, D., and Reichlin, L. (2010). Large bayesian vector auto regressions. Journal of Applied Econometrics, 25(1):71-92.

Barsky, R. B., Basu, S., and Lee, K. (2014). Whither news shocks? NBER chapters (NBER Macroeconomics Annual 2014), 29.

Barsky, R. B. and Sims, E. R. (2011). News shocks and business cycles. Journal of Monetary Economics, 58(3):273-289.

Basu, S., Fernald, J. G., Fisher, J., and Kimball, M. S. (2013). Sector-specific technological change. Manuscript. 
Basu, S., Fernald, J. G., and Kimball, M. S. (2006). Are technology improvements contractionary? American Economic Review, 96(5):1418-1448.

Beaudry, P. and Portier, F. (2006). Stock prices, news, and economic fluctuations. American Economic Review, 96(4):1293-1307.

Beaudry, P. and Portier, F. (2014). News-driven business cycles: insights and challenges. Journal of Economic Literature, 52(4):993-1074.

Carriero, A., Clark, T. E., and Marcellino, M. (2015). Bayesian vars: specification choices and forecast accuracy. Journal of Applied Econometrics, 30(1):46-73.

Estrella, A. and Hardouvelis, G. A. (1991). The term structure as a predictor of real economic activity. Journal of Finance, 46(2):555-76.

Faust, J. (1998). The robustness of identified var conclusions about money. CarnegieRochester Conference Series on Public Policy, 49:207-244.

Fernald, J. G. (2014). A quarterly, utilization-adjusted series on total factor productivity. FRBSF Working Paper (updated in March 2014), 2012-19.

Forni, M., Gambetti, L., and Sala, L. (2014). No news in business cycles. Economic Journal, 124(581):1168-1191.

Gilchrist, S. and Zakrajšek, E. (2012). Credit spreads and business cycle fluctuations. American Economic Review, 102:1692-1720.

Harvey, C. R. (1988). The real term structure and consumption growth. Journal of Financial Economics, 22(2):305-333.

Kurmann, A. and Otrok, C. (2011). News shocks and the term structure of interest rates: a challenge for dsge models. Society for Economic Dynamics 2011 Meeting Papers, 426.

Kurmann, A. and Otrok, C. (2013). News shocks and the slope of the term structure of interest rates. American Economic Review, 103(6):2612-32.

Litterman, R. B. (1986). Forecasting with bayesian vector autoregressions: five years of experience. Journal of Business \& Economic Statistics, 4(1):25-38. 
Uhlig, H. (2005). What are the effects of monetary policy on output? results from an agnostic identification procedure. Journal of Monetary Economics, 52:381-419.

\section{A Appendix}

Figure 8: Fraction of forecast error variance explained by a news shock with the new version of the utilization-adjusted TFP under the Kurmann and Otrok (2013) model
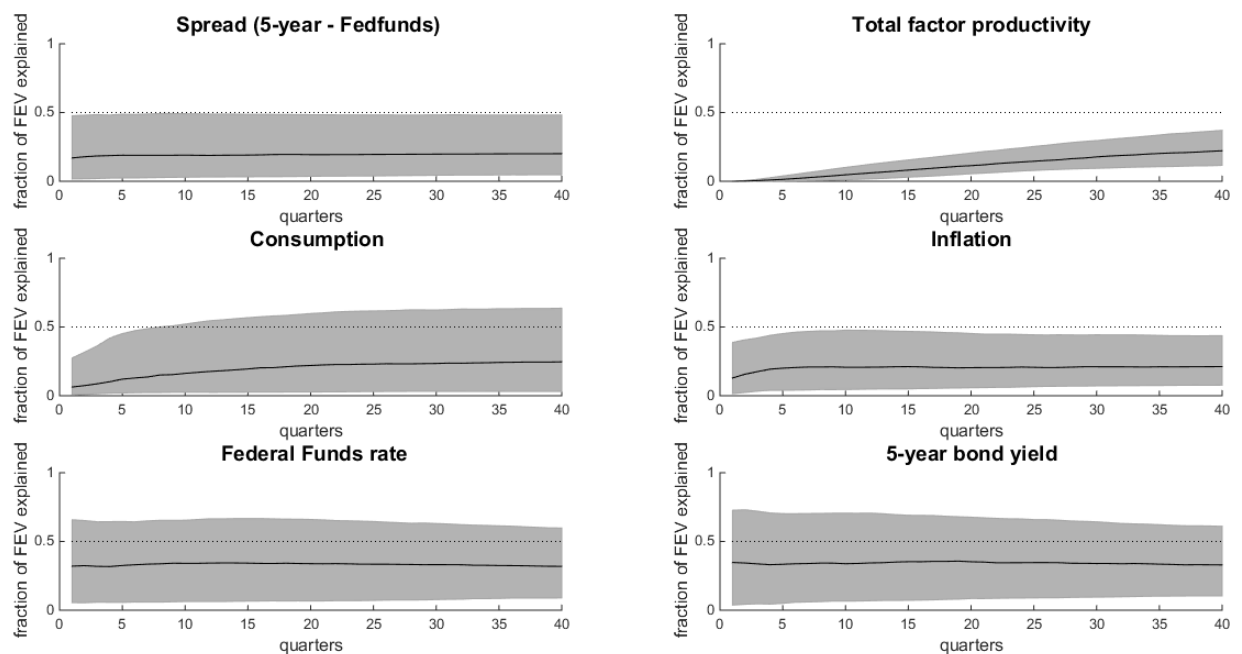

The grey area corresponds to the 16\%-84\% coverage bands of the model considering the new TFP series. 
Figure 9: Correlations between news and slope shocks on an 80 quarter moving window from an alternative VAR model augmented by financial variables and considering the old utilization-adjusted TFP series

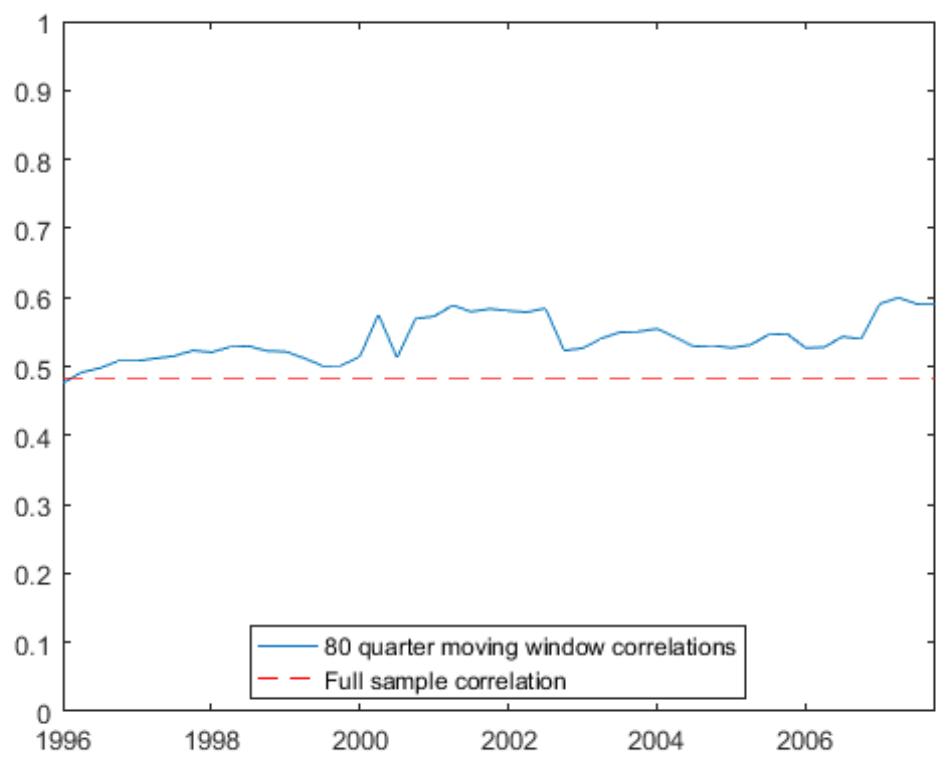

Calculation of correlations between the recovered news and slope shocks over an 80 quarter moving window under the original identification of Kurmann and Otrok (2013). The correlation over the full sample (from 1975:I to 2007:IV) is of 0.48. The date in the horizontal axis corresponds to the final observation of the 80 quarter moving window. 